\title{
Probing Critical Physical Properties of Lactose-Polyethylene Glycol Microparticles in Pulmonary Delivery of Chitosan Nanoparticles
}

\author{
Nasser Alhajj ${ }^{1,2}$, Idanawati Naharudin ${ }^{1,2}$, Paolo Colombo ${ }^{3,4, *}$, Eride Quarta ${ }^{4}$ (D) and Tin Wui Wong ${ }^{1,2,5, *}$ \\ 1 Non-Destructive Biomedical and Pharmaceutical Research Centre, Smart Manufacturing Research Institute, \\ Universiti Teknologi MARA Selangor, Puncak Alam 42300, Selangor, Malaysia; nasserph@hotmail.com (N.A.); \\ idana482@uitm.edu.my (I.N.) \\ 2 Particle Design Research Group, Faculty of Pharmacy, Universiti Teknologi MARA Selangor, \\ Puncak Alam 42300, Selangor, Malaysia \\ 3 PlumeStars srl, 43125 Parma, Italy \\ 4 Food and Drug Department, University of Parma, 43121 Parma, Italy; eride.quarta@studenti.unipr.it \\ 5 Sino-Malaysia Molecular Oncology and Traditional Chinese Medicine Delivery Joint Research Centre, \\ Medical College, Yangzhou University, 136, Jiangyang Middle Road, Yangzhou 225001, China \\ * Correspondence: paolo.colombo@plumestars.com (P.C.); wongtinwui@uitm.edu.my (T.W.W.); \\ Tel.: +60-19-359-4691 (T.W.W.)
}

check for updates

Citation: Alhajj, N.; Naharudin, I.; Colombo, P.; Quarta, E.; Wong, T.W. Probing Critical Physical Properties of Lactose-Polyethylene Glycol Microparticles in Pulmonary Delivery of Chitosan Nanoparticles. Pharmaceutics 2021, 13, 1581. https:/ / doi.org/10.3390/pharmaceutics13101581

Academic Editors: Franca Ferrari,

Maria Cristina Bonferoni and

César Viseras

Received: 4 September 2021

Accepted: 26 September 2021

Published: 29 September 2021

Publisher's Note: MDPI stays neutral with regard to jurisdictional claims in published maps and institutional affiliations.

Copyright: (C) 2021 by the authors. Licensee MDPI, Basel, Switzerland. This article is an open access article distributed under the terms and conditions of the Creative Commons Attribution (CC BY) license (https:/ / creativecommons.org/licenses/by/ $4.0 /)$.

\begin{abstract}
Pulmonary delivery of chitosan nanoparticles is met with nanoparticle agglomeration and exhalation. Admixing lactose-based microparticles (surface area-weighted diameter $5 \mu \mathrm{m}$ ) with nanoparticles mutually reduces particle agglomeration through surface adsorption phenomenon. Lactose-polyethylene glycol (PEG) microparticles with different sizes, morphologies and crystallinities were prepared by a spray drying method using varying PEG molecular weights and ethanol contents. The chitosan nanoparticles were similarly prepared. In vitro inhalation performance and peripheral lung deposition of chitosan nanoparticles were enhanced through co-blending with larger lactose-PEG microparticles with reduced specific surface area. These microparticles had reduced intermicroparticle interaction, thereby promoting microparticle-nanoparticle interaction and facilitating nanoparticles flow into peripheral lung.
\end{abstract}

Keywords: chitosan; lactose; microparticle; nanoparticle; pulmonary delivery

\section{Introduction}

Lactose is widely used in inhalation dosage form development with reference to dry powder aerosol [1-4]. It is safe, and exhibits good physicochemical stability and powder flow properties [5]. Lactose, mannitol, sorbitol and dextran are inhalational sugar and polyalcohol carriers for drugs [6], but the only approved carrier is lactose [4].

The United States Food and Drug Administration indicates that a nanoproduct has at least one nanoscale dimension (about $1 \mathrm{~nm}$ to $100 \mathrm{~nm}$ ), or exhibits physicochemical or biological properties attributable to its nanogeometry, up to one $\mu \mathrm{m}$ [7]. The nanocarrier presents several advantages in pulmonary dosage form design: (I) the nanocarrier has a large specific surface area to interact with the lung; (II) cell- and organelle-targeting can be elicited by decorating nanocarrier with targeting ligand; and (III) the nanocarrier is characterized by a higher lung cell uptake, leading to reduced required drug dosage and side effects $[8,9]$.

Chitosan is widely explored as a pulmonary therapeutic carrier in lung cancer therapy [10-16]. The pulmonary chitosan carrier brings about reduced systemic drug toxicity, increased lung drug bioavailability and improved anti-cancer drug efficacy. The cellular uptake of engineered particles is improved and cancer cell apoptosis is promoted [10-16].

Chitosan nano- and micro-carriers have been developed as pulmonary drug vehicles $[15,17,18]$. The suitability of chitosan solid nanoparticles and liquid nanoemulsion 
for pulmonary drug delivery has been examined. The solid nanoparticles are prone to exhalation where particles less than $1 \mu \mathrm{m}$ can be exhaled up to $80 \%$ after inspiration without being deposited, unlike particles with an aerodynamic diameter between 1 and $3 \mu \mathrm{m}$, which can be delivered into the lower lung $[19,20]$. They are highly aggregative with inefficient dispersion and inhalation performances $[19,20]$. The solid nanoparticles have been co-spray dried with leucine, lactose, maltodextrin or mannitol into microparticles or physically admixed with lactose-polyethylene glycol 3000 microparticles to promote their inhalation efficiency [20-22]. The co-spray dried microparticles are small (mass median aerodynamic diameter $=3-10 \mu \mathrm{m}$ ) [22]. They are, however, aggregative and not desirable for pulmonary inhalation $[5,23]$. Blending of co-spray dried microparticles with large carriers $(63-90 \mu \mathrm{m})$ improves microparticle dispersibility [5]. The large carrier carries the microparticles through surface adsorption. The microparticles were detached from the large carrier during the inhalation process and were deposited in the lung [24].

A direct chitosan nanoparticles-lactose-polyethylene glycol 3000 microparticle blend enhances the powder flow, similar to the microparticles-large carriers mix [20,24,25]. Microparticles as well as nanoparticles are cohesive. Dispersing the nanoparticles over the microparticles' surfaces through mixing in a specific weight ratio promotes the dispersibility of nanoparticles [26]. The adsorbed nanoparticles are functionally a glidant. They can reduce the aggregation of microparticles to produce an inhalable powder.

Unlike co-spray drying, direct chitosan nanoparticles-lactose based microparticle blending reduces the likelihood of changes in nanoparticulate properties $[20,27,28]$. The size-dependent biological responses of nanoparticles are expected to deviate to a lesser extent by blending than microencapsulation by co-spray drying $[20,27,28]$. The surfacedeposited nanoparticles are re-dispersible. They can detach more readily from the microparticle surfaces and are inhaled into the lung with a reduced entanglement tendency as per the microencapsulated system.

The size and shape, as well as specific surface area, of nanoparticles, admixed with lactose-based microparticles, affect their inhalation efficiency [20]. Small and irregularly shaped nanoparticles have a large specific surface area and are aggregative. They are not deposited onto the surfaces of microparticles and experience a low inhalation efficiency. Over the past few decades, the majority of inhalation studies focus to identify the critical physicochemical attributes of large carriers for pulmonary delivery of microparticles $(3 \mu \mathrm{m}$ to $10 \mu \mathrm{m}$ ). There is no known study evaluating the critical design of microparticles as the pulmonary carrier of nanoparticles. The latter represents a greater challenge as both nanoparticles and microparticles are cohesive. Both nanoparticles and microparticles are relatively cohesive in that they are small in size and are characterized by a large interparticulate-specific surface area. To enable nanoparticles to adsorb on the microparticulate surfaces and to transform into an inhalable formulation, it is hypothesized that larger, rounder and smoother microparticles are required to enable nanoparticles to disaggregate and adsorb onto the microparticulate surfaces without developing a cohesive blend. As such, this study assesses the inhalation performances of chitosan nanoparticles-lactosepolyethylene glycol microparticle blends using microparticles developed with different physicochemical characteristics. The study aims to identify the critical properties of lactosepolyethylene glycol microparticles that are required to deliver the chitosan nanoparticles by inhalation means.

\section{Materials and Methods}

\subsection{Materials}

Lactose monohydrate (Sorbolac 400, Meggle, Wasserburg, Germany) was used as the matrix material of microparticles. Polyethylene glycol 400, 1000 and 3000 (PEG 400, PEG 1000, PEG 3000; Merck, Darmstadt, Germany) were used as the stabilizers with ethanol absolute (Merck, Germany) as the additive. Chitosan (molecular weight: 20,000-50,000 g/mol, degree of deacetylation $\geq 90 \%$; Zhejiang Aoxing Biotechnology Co. Ltd., Zhejiang, China) was used as the model matrix material that was transformable into nanoparticles, with 
glacial acetic acid as a solvent (Merck, Germany). Lithium acetate anhydrous (ACROS Organics ${ }^{\mathrm{TM}}$, Waltham, MA, USA), ninhydrin and hydrindantin (Sigma-Aldrich, Saint Louis, $\mathrm{MO}, \mathrm{USA}$ ) were the reagents used for the quantitative assay of chitosan.

\subsection{Preparation of Lactose-PEG Microparticles}

Lactose microparticles L1-6 were prepared by a spray drying technique (Table 1; TwinNanoSpray, UiTM, Selangor, Malaysia). The lactose was first dissolved in the distilled water. It was then added with $2.5 \% \mathrm{w} / \mathrm{w}$ PEG, with reference to dry lactose weight, at $25 \pm 1{ }^{\circ} \mathrm{C}$. When applicable, the ethanol was introduced as the co-solvent of lactose and PEG. PEGs were used as the stabilizer of lactose microparticles. Their molecular weights ranged from 400 to $3000 \mathrm{~g} / \mathrm{mol}$.

Table 1. Formulation and process parameters of lactose-PEG microparticles.

\begin{tabular}{ccccccc}
\hline Formulation/Processing Condition & L1 & L2 & L3 & L4 & L5 & L6 \\
\hline Lactose concentration $(\% \mathrm{w} / \mathrm{w})$ & 2 & 2 & 2 & 2 & 2 & 2.5 \\
PEG concentration $(\% \mathrm{w} / \mathrm{w})$ & 2.5 & 2.5 & 2.5 & 2.5 & 2.5 \\
PEG molecular weight $(\mathrm{g} / \mathrm{mol})$ & 400 & 1000 & 3000 & 400 & 1000 & 3000 \\
Ethanol concentration $(\% \mathrm{w} / \mathrm{w})$ & 0 & 0 & 0 & 50 & 50 & 50 \\
Feeding rate $(\mathrm{mL} / \mathrm{min})$ & 2 & 2 & 70 & 70 & 70 & 70 \\
Inlet temperature $\left({ }^{\circ} \mathrm{C}\right)$ & 70 & 70 & 27.5 & 26.9 & 27.3 & 27.6 \\
Outlet temperature $\left({ }^{\circ} \mathrm{C}\right)$ & 26 & 25.6 & 5.5 & 5.5 & 5.5 \\
Atomizing pressure $(\mathrm{bar})$ & 5.5 & 5.5 & 5.5 & 2 \\
\hline
\end{tabular}

The spray-dried powder was collected by a precipitating electrode. It was kept in a 30-mL glass jar. The powder was stored in a desiccator at $25 \pm 1{ }^{\circ} \mathrm{C}$ for 5 days prior to characterization.

\subsection{Preparation of Chitosan Nanoparticles}

Chitosan $(0.1 \% \mathrm{w} / \mathrm{w})$ was dissolved in $0.5 \% \mathrm{v} / \mathrm{v}$ acetic acid under continuous stirring for $5 \mathrm{~h}$ at $25 \pm 1{ }^{\circ} \mathrm{C}$. The solution was subjected to nanospray-drying (TwinNanoSpray, UiTM, Malaysia) with inlet temperature $=70^{\circ} \mathrm{C}$, outlet temperature $=24.8^{\circ} \mathrm{C}$, solution feed rate $=3 \mathrm{~mL} / \mathrm{min}$ via bifeeding tubes, and atomizing air pressure $=6 \mathrm{bar}$. The spray-dried powder was collected at the precipitating electrode. It was retrieved into a $10 \mathrm{~mL}$ clear glass powder jar by a rubber spatula. The powder was stored in a desiccator at $25 \pm 1{ }^{\circ} \mathrm{C}$ prior to characterization.

\subsection{Physicochemical Analysis of Lactose-PEG Microparticles}

\subsubsection{Density}

A known weight of powder was added in a 5-mL measuring cylinder. The quotient of powder weight to bulk volume was recorded as the bulk density $(\rho b)$. The cylinder was subjected to 200 taps, where there was no further powder bed volume reduction thereafter, at 4 taps/s. The tapped density $(\rho t)$ was recorded as the quotient of powder weight to its tapped volume. Both bulk density and tapped density values of powder were used to derive Carr's index and Hausner ratio by means of the following equations:

$$
\begin{gathered}
\text { Carr's index }=(1-\rho b / \rho t) \times 100 \% \\
\text { Hausner ratio }=\rho t / \rho b
\end{gathered}
$$

\subsubsection{Size}

The size distribution of microparticles was determined using the laser diffraction analyzer (Mastersizer 2000, Malvern Instruments Ltd., Worcestershire, UK). The volume weighted mean diameter $\left(D_{[4,3]}\right)$, surface area weighted mean diameter $\left(D_{[3,2]}\right)$, specific surface area, span, volume median diameter $d_{10}, d_{50}$ and $d_{90}$ were assessed by means of 
dry powder dispersion mode (Scirocco 2000) at 1 bar pressure. Triplicates were run for each type of microparticles with the results averaged.

\subsubsection{Scanning Electron Microscopy}

The surface morphology of microparticles was evaluated by scanning electron microscope (SEM) (Quanta 450 FEG, FEI, Eindhoven, The Netherlands). The microparticles were adhered onto a carbon tape, and sputter-coated with $5 \mathrm{~nm}$-thick platinum with an auto fine coater (JFC-1600, JEOL, Akishima, Japan). The surface roughness $\left(\mathrm{R}_{\mathrm{a}}\right)$ and circularity (Circ) of microparticles were analyzed by ImageJ software (NiH, Bethesda, MD, USA). A minimum of nine measurements of three images were characterized.

\subsubsection{X-ray Powder Diffraction}

The crystallinity of microparticles was examined by the X-ray powder diffractometer (XRPD) (Ultima IV, Rigaku Coperation, Akishima, Japan), over diffraction angles $(2 \theta)$ of $3^{\circ}$ to $60^{\circ}$ at $5^{\circ} / \mathrm{min}$ scanning speed. $\mathrm{Cu}-\mathrm{K} \alpha(40 \mathrm{kV}$ and $30 \mathrm{~mA})$ was used as the $\mathrm{X}$-ray resource. Triplicates were conducted and the results were averaged.

\subsection{Physicochemical Characterization of Chitosan Nanoparticles}

The surface morphology and crystallinity of the chitosan nanoparticles were examined by SEM and XRPD techniques respectively. The chitosan crystallinity index (cCI; \%) was calculated as:

$$
\mathrm{cCI}=\frac{\left(\mathrm{I}_{110}-\mathrm{I}_{\mathrm{amor}}\right) \times 100}{\mathrm{I}_{110}}
$$

where $\mathrm{I}_{110}=$ maximum intensity at $20^{\circ}$ and $\mathrm{I}_{\mathrm{amor}}=$ intensity of amorphous diffraction at $16^{\circ}[29,30]$.

\subsubsection{Size}

The size and polydispersity index were determined using the Zetasizer (Nano ZS 90, Malvern Instruments Ltd., Worcestershire, UK) at $25 \pm 1{ }^{\circ} \mathrm{C}$ and $90^{\circ}$ scattering angle. The nanoparticles $(5 \mathrm{mg})$ were dispersed in deionized water $(30 \mathrm{~mL})$ with the aid of magnetic stirring. Triplicates were determined with results averaged.

\subsubsection{Zeta Potential}

The zeta potential was determined using the Zetasizer (Nano ZS 90, Malvern Instruments Ltd., Worcestershire, UK) at $25 \pm 1{ }^{\circ} \mathrm{C}$. The nanoparticles (5 mg) were dispersed in deionized water $(30 \mathrm{~mL})$ with the aid of magnetic stirring. Three measurements were determined with results averaged.

\subsection{In Vitro Aerosolization and Inhalation}

Andersen Cascade Impactor (Copley Scientific Ltd., Nottingham, UK) was used to assess the aerosolization and inhalation profiles of nanoparticles as a function of physicochemical characteristics of lactose-PEG microparticles. The stage F-0 were assembled with silicone rubber O-rings to avoid leakage from gaps between stages. A glass fiber filter (Copley Scientific Ltd., Nottingham, UK) was placed beneath stage 7 to capture small particles from upper stages. A pre-separator was attached to stage 0 with a connecting induction port assembled with mouthpiece adapter and Handihaler ${ }^{\circledR}$ (Boehringer Ingelheim, Ingelheim am Rhein, Germany). The impactor was equipped with a vacuum source (LCP5, Copley Scientific Ltd., Nottingham, UK) and a critical flow controller (TPK 2000, Copley Scientific Ltd., Nottingham, UK).

The chitosan nanoparticles and lactose-PEG microparticles (weight ratio 1:9) were blended with $40 \mathrm{~Hz}$ vortex for $30 \mathrm{~min}$ (VelpScientifica, Usmate, Italy). Thirty mg of powder mixture were inserted into a size- 2 capsule (San Tronic Medical Devices, Selangor, Malaysia). The capsule was inserted into the chamber of Handihaler ${ }^{\circledR}$. The powder in the inhaler was actuated to the impactor through an air current flow of $48 \mathrm{~L} / \mathrm{min}$ for $5 \mathrm{~s}$ 
which corresponded to a $4 \mathrm{kPa}$ pressure drop as in human lung. The cut-off diameter of each stage was calculated using Equation (4): Stage 0, $6.91 \mu \mathrm{m}$; Stage 1, $4.45 \mu \mathrm{m}$; Stage 2, $3.61 \mu \mathrm{m}$; Stage 3, $2.53 \mu \mathrm{m}$; Stage 4, $1.61 \mu \mathrm{m}$; Stage 5, $0.84 \mu \mathrm{m}$; Stage 6, $0.54 \mu \mathrm{m}$; and Stage 7, $0.31 \mu \mathrm{m}$.

$$
\mathrm{D}_{50,48}=\mathrm{D}_{50,28.3}\left(\frac{28.3}{48}\right)^{\frac{1}{2}}
$$

where $D_{50,48}$ and $D_{50,28.3}$ are the cut-off diameters at 48 and $28.3 \mathrm{~L} / \mathrm{min}$ respectively.

The contents of 5 capsules (15 mg chitosan nanoparticles) were released into the impactor sequentially in a cumulative fashion. Triplicates were conducted, and with impactor cleaned before another 5 capsules were tested. The emitted powders on mouthpiece, induction port, pre-separator, collection plate and filter were collected using $0.5 \% \mathrm{v} / \mathrm{v}$ acetic acid solution. The samples were stored in individual glass vials, oscillated in a shaker bath (ST402, Nuve, Ankara, Turkey) at $25 \pm 1^{\circ} \mathrm{C}$ for $5 \mathrm{~h}$, and had chitosan content determined by ninhydrin assay method. The chitosan content was assayed using UV-VIS spectrophotometer (Cary 50 Conc, Varian Australia Pty. Ltd., Mulgrave, Australia) at $570 \mathrm{~nm}$ wavelength. The detection and quantification limits were $0.048 \mathrm{mg} / \mathrm{mL}$ and $0.160 \mathrm{mg} / \mathrm{mL}$ respectively. The linearity ranged between 0.025 and $1.000 \mathrm{mg} / \mathrm{mL}$.

The emitted dose (ED) referred to the collective chitosan mass on mouthpiece, induction port, pre-separator and all stages. Deposited dose (DD) referred to chitosan mass on stages 0 to F. Percent dispersed (PD) was defined as percentage ED in relation to total dose (TD). Percent inhaled (PI) was defined as percentage DD in relation to TD. The fine particle doses (FPD), $\mathrm{FPD}_{<4.5 \mu \mathrm{m}}, \mathrm{FPD}_{<3.6 \mu \mathrm{m}}$, and $0.5 \mu \mathrm{m}<\mathrm{FPD}_{<3.6 \mu \mathrm{m}}$, were doses on stages 2 to $\mathrm{F}$, stages 3 to $\mathrm{F}$, and stages 3 to 7 respectively. $\mathrm{FPD}_{<4.5 \mu \mathrm{m}}$ reflected deep lung-deposited particles. $\mathrm{FPD}_{<3.6 \mu \mathrm{m}}$ reflected peripheral lung-deposited particles. $0.5 \mu \mathrm{m}<\mathrm{FPD}_{<3.6 \mu \mathrm{m}}$ represented $\mathrm{FPD}_{<3.6 \mu \mathrm{m}}$ excluding particles prone to exhalation $(<500 \mathrm{~nm})$. The fine particle fraction (FPF) was defined as percentage FPD to ED. The respirable fraction (RF) was denoted by percentage of FPD to DD.

The cumulative particle size distribution pattern was plotted on a log probability graph. The particle size at 50th percentile of distribution was denoted as mass median aerodynamic diameter (MMAD). The square root of the ratio of particle size at 84.13 th percentile to 15.87 th percentile was denoted as a geometric standard deviation (GSD). Triplicates were run for each experiment with the results averaged.

\subsection{Fourier Transform Infrared (FTIR) Spectroscopy}

The segregation pattern of chitosan nanoparticles from lactose-PEG microparticles upon inhalation was characterized. L3 and L6 admixed with chitosan nanoparticles were collected from stages 0 to 7 . The powder mixture was blended with potassium bromide at a 1:99 weight ratio and was subjected to grinding. The ground mixture was compressed by an axial load (Specac Ltd., Kent, UK) to a maximum pressure of 10 tons for $2 \mathrm{~min}$. The FTIR spectrum of the formed disc was obtained by an IR spectrometer (Spectrum 100, Perkin Elmer, Richmond, UK) through scanning over 400 to $4000 \mathrm{~cm}^{-1}$ and at $4 \mathrm{~cm}^{-1}$ resolution. Chitosan nanoparticles, lactose-PEG microparticles and the mixture of both (weight ratio 1:9) were used as the references. The correlation of FTIR spectra between impactor powder samples and references was analyzed using Perkin Elmer Spectrum Version 10.3.6 software (Perkin Elmer, Richmond, UK) by means of the following equation [20]:

$$
\text { Correlation coefficient }=\frac{\sum w_{i} A_{i} B_{i}}{\left(\sum w_{i} A_{i} A_{i}\right)^{0.5} \times\left(\sum w_{i} B_{i} B_{i}\right)^{0.5}}
$$

where $A_{i}=$ spectra absorbance value of test powder at frequency $i, B_{i}=$ spectra absorbance value of reference powder at frequency $i$, and $w_{i}=$ a statistical weighting factor. Triplicates of experiment were conducted with results averaged. 


\section{Results and Discussion}

\subsection{Physicochemical Characteristics of Lactose-PEG Microparticles}

The physicochemical characteristics of six lactose-PEG microparticle variants are summarized in Table 2.

Table 2. Physicochemical attributes of lactose-PEG microparticles.

\begin{tabular}{ccccccc}
\hline Particle Characteristic & L1 & L2 & L3 & L4 & L5 & L6 \\
\hline Crystallinity (Peak & $888.27 \pm 3.36$ & $705.57 \pm 14.10$ & $508.73 \pm 11.98$ & $612.90 \pm 17.90$ & $764.03 \pm 2.00$ & $618.53 \pm 13.48$ \\
area $\left.2 \theta=19.98^{\circ}\right)$ & $0.150 \pm 0.002$ & $0.119 \pm 0.001$ & $0.102 \pm 0.002$ & $0.112 \pm 0.003$ & $0.091 \pm 0.002$ & $0.113 \pm 0.002$ \\
$p b\left(\mathrm{~g} / \mathrm{cm}^{3}\right)$ & $0.283 \pm 0.005$ & $0.310 \pm 0.001$ & $0.212 \pm 0.003$ & $0.313 \pm 0.002$ & $0.252 \pm 0.003$ & $0.271 \pm 0.002$ \\
$p t\left(\mathrm{~g} / \mathrm{cm}^{3}\right)$ & $46.98 \pm 1.67$ & $61.51 \pm 0.22$ & $51.91 \pm 0.13$ & $64.25 \pm 1.07$ & $63.99 \pm 0.52$ & $58.47 \pm 0.80$ \\
Carr's Index $(\%)$ & $1.89 \pm 0.06$ & $2.60 \pm 0.02$ & $2.08 \pm 0.01$ & $2.80 \pm 0.08$ & $2.78 \pm 0.04$ & $2.41 \pm 0.05$ \\
Hausner Ratio & $0.12 \pm 0.01$ & $0.14 \pm 0.02$ & $0.16 \pm 0.06$ & $0.22 \pm 0.02$ & $0.27 \pm 0.02$ & $0.16 \pm 0.02$ \\
Circ & $129.73 \pm 7.62$ & $75.19 \pm 1.47$ & $127.21 \pm 1.11$ & $114.70 \pm 17.83$ & $86.24 \pm 2.91$ & $122.84 \pm 1.25$ \\
Ra (nm) & $1.49 \pm 0.08$ & $1.24 \pm 0.02$ & $1.90 \pm 0.01$ & $1.55 \pm 0.04$ & $0.99 \pm 0.02$ & $1.31 \pm 0.20$ \\
Specific surface area & $23.09 \pm 0.64$ & $19.23 \pm 0.14$ & $20.61 \pm 1.04$ & $15.53 \pm 1.54$ & $18.11 \pm 3.44$ & $20.74 \pm 1.62$ \\
$\left(\mathrm{~m}^{2} / \mathrm{g}\right)$ & $4.03 \pm 0.25$ & $4.84 \pm 0.07$ & $3.15 \pm 0.02$ & $3.87 \pm 0.20$ & $6.07 \pm 0.14$ & $4.62 \pm 0.69$ \\
$\mathrm{D}_{[4,3]}(\mu \mathrm{m})$ & $6.57 \pm 0.19$ & $3.20 \pm 0.04$ & $9.76 \pm 0.15$ & $4.08 \pm 0.27$ & $2.05 \pm 0.07$ & $4.20 \pm 0.35$ \\
$\mathrm{D}_{[3,2]}(\mu \mathrm{m})$ & $1.72 \pm 0.06$ & $2.62 \pm 0.06$ & $1.58 \pm 0.01$ & $1.72 \pm 0.04$ & $4.02 \pm 0.10$ & $1.91 \pm 0.18$ \\
Span & $9.33 \pm 1.01$ & $13.23 \pm 0.18$ & $5.43 \pm 0.10$ & $8.30 \pm 0.27$ & $13.32 \pm 0.15$ & $10.44 \pm 0.48$ \\
$\mathrm{~d}_{10}(\mu \mathrm{m})$ & $63.03 \pm 4.79$ & $43.60 \pm 1.14$ & $54.60 \pm 1.70$ & $35.59 \pm 1.86$ & $31.30 \pm 1.26$ & $45.89 \pm 5.85$ \\
$\mathrm{~d}_{50}(\mu \mathrm{m})$ & &
\end{tabular}

$p b$ : bulk density; $p t$ : tapped density; Ra: surface roughness; $\mathrm{D}_{[4,3]}$ : volume weighted mean diameter; $\mathrm{D}_{[3,2]}$ : surface area weighted mean diameter; $\mathrm{d}_{10}$ : particle diameter corresponding to $10 \%$ undersized fraction; $\mathrm{d}_{50}$ : particle diameter corresponding to $50 \%$ undersized fraction; $\mathrm{d}_{90}$ : particle diameter corresponding to $90 \%$ undersized fraction.

\subsubsection{Size}

Lactose-PEG microparticles were characterized by $d_{50}$ ranging from $5.43 \pm 0.10 \mu \mathrm{m}$ (L3) to $13.32 \pm 0.15 \mu \mathrm{m}$ (L5) (Table 2). PEG 3000 had a lower affinity for water than PEG 400 and PEG 1000 [31]. With reference to L3, it was envisaged that the spray droplets were small due to reduced PEG-water tension. The dried particles were thus accordingly small.

Lactose is soluble in water $\left(0.22 \mathrm{~g} / \mathrm{mL}\right.$ at $\left.25^{\circ} \mathrm{C}\right)$. It is practically ethanol-insoluble. PEG is soluble in ethanol, with a larger molecular weight PEG having a higher solubility [31]. In the case of L6, the lactose was envisaged to accumulate in the aqueous phase. PEG 3000 was attracted to the organic phase. Larger spray droplets were anticipated due to reduced contact of lactose-PEG. The size of spray-dried particles in the presence of ethanol was larger than in the ethanol-free sample (L3). The effect of ethanol on particle size was not apparent with PEG 400 and PEG 1000. Being lower in molecular weight, these PEGs had a higher affinity to water than ethanol. The formation of spray-dried particles was less affected by ethanol.

\subsubsection{Morphology}

All batches of lactose-PEG microparticles were irregular in shape with some variations (Figure 1; Table 2). In terms of surface roughness, L2 and L5 that were formulated with PEG 1000 had a noticeable lower Ra values (Table 2). PEG 400 had a lower tackiness than PEG 1000. Its use might be accompanied by irregular contact with the lactose due to poor attachment property. In the case of PEG 3000, the higher viscosity PEG was envisaged to exhibit a poor spread over lactose. The summative effect was that PEG with molecular weight higher or lower than $1000 \mathrm{~g} / \mathrm{mol}$ brought about the formation of lactose-PEG microparticles with rougher surfaces. 

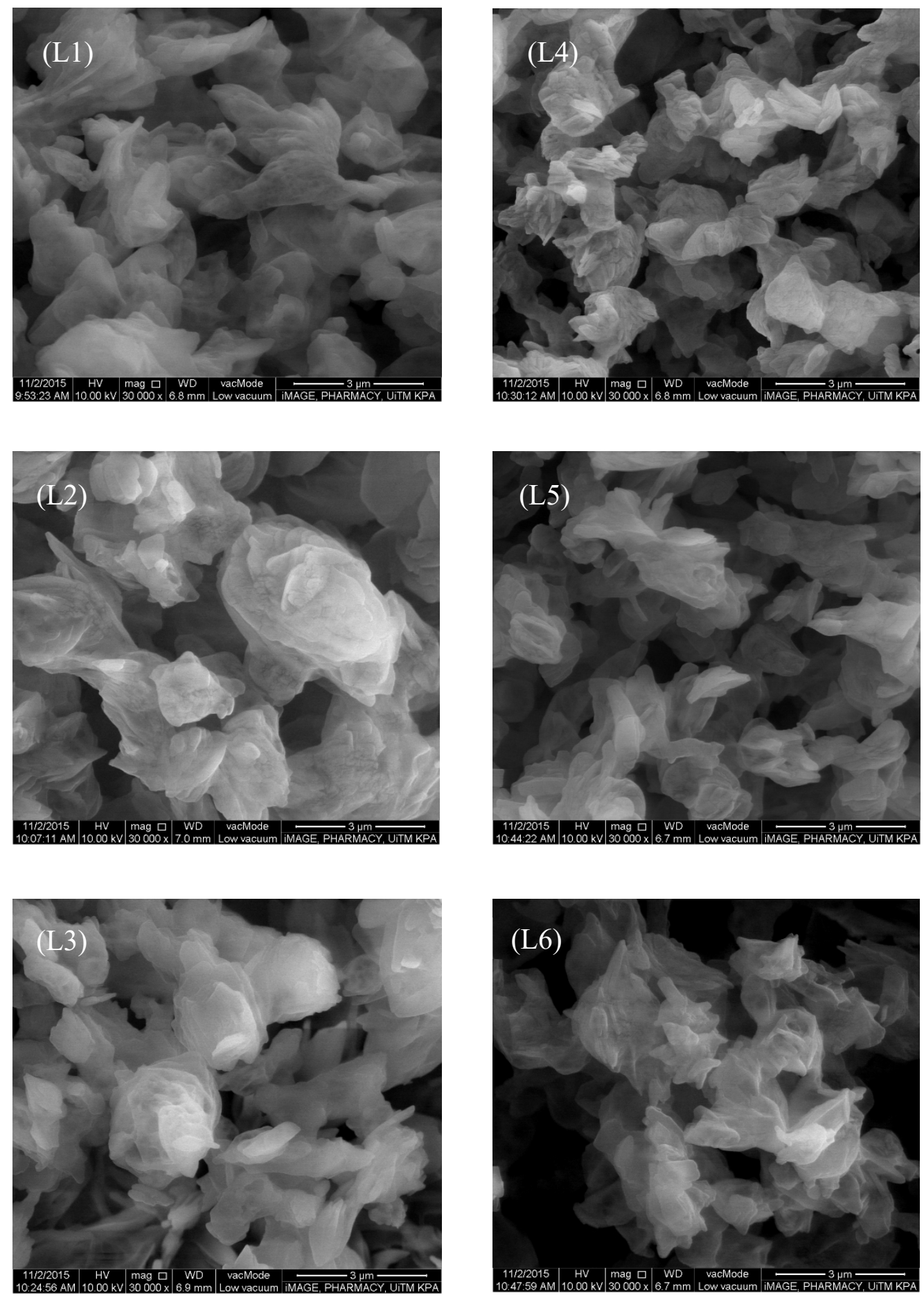

Figure 1. Scanning electron microscopic images of lactose-PEG microparticles.

\subsubsection{Crystallinity}

The spray-dried lactose microparticles were hygroscopic and experienced a marked aggregation during handling. PEG could transform the spray-dried lactose with a higher crystallinity level. It could form hydrogen bonds with water in the course of spray drying. The PEG could delay the lactose drying and provide more time for lactose molecules to rearrange into a crystalline structure [32,33].

The crystallinity of L1 to L6 microparticles were lower than unprocessed lactose (peak area $_{2 \theta}=19.98^{\circ}=1640.67 \pm 75.13$ ) and higher than PEG-free spray-dried lactose (peak $\operatorname{area}_{2 \theta=19.98^{\circ}}=15.85 \pm 7.14$ ) (Table 2; Figure 2). In the case of L1 and L4, the ethanol-free 
formulation exhibited a higher matrix crystallinity. Using ethanol as an additive, the drying rate of spray droplets was anticipated to be fast and resulted in the formation of more amorphous lactose-PEG microparticles. Lower molecular weight PEG is less interactive with ethanol [31]. The speed of drying droplets with a lower molecular weight PEG can be promoted by ethanol to an extent where matrix crystallinity was reduced to a noticeable degree.

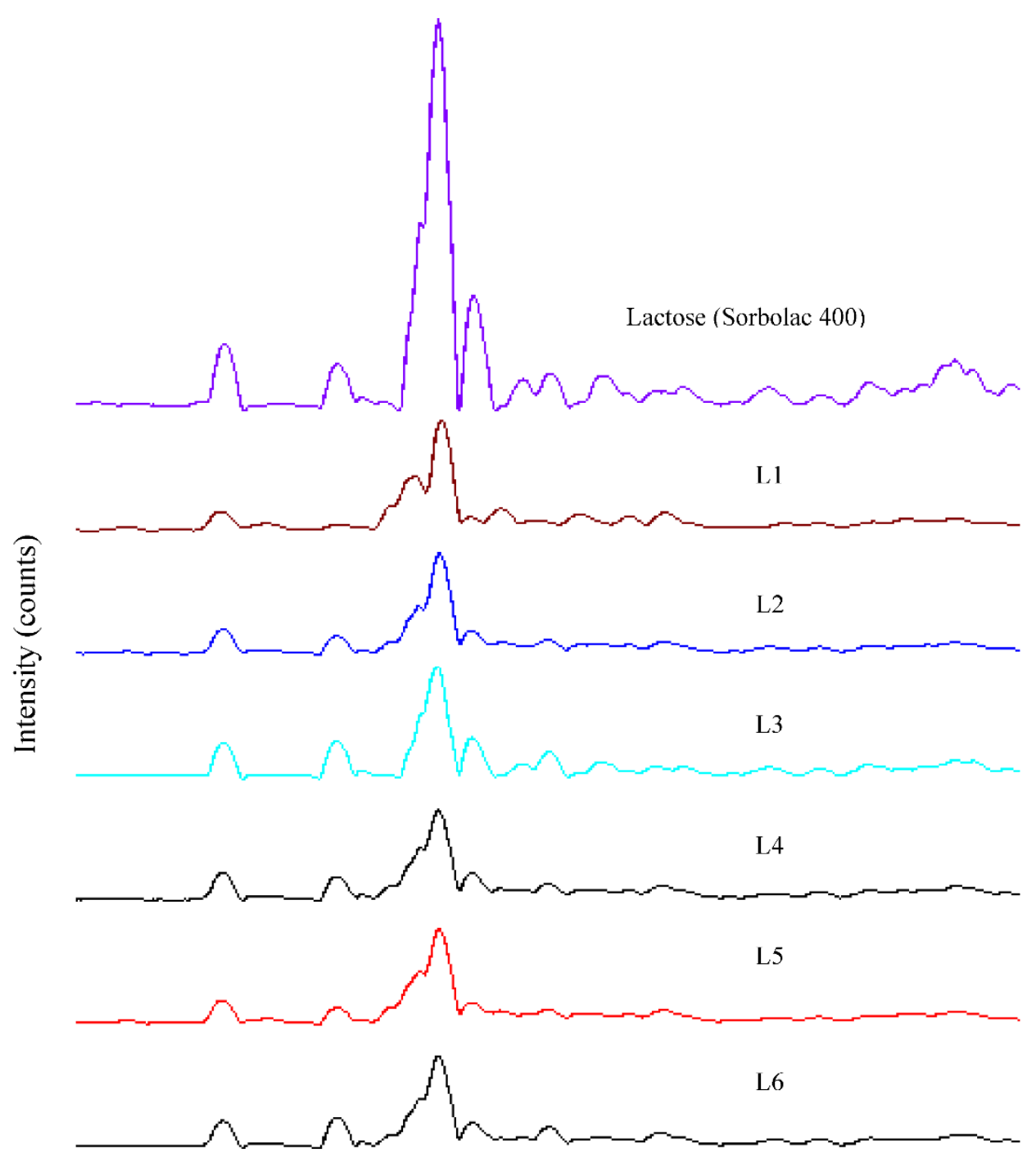

PEG-Free spray-dried lactose

$\stackrel{10.0000}{\frac{1}{20.0000}}=\frac{1}{30.0000}$

Figure 2. X-ray powder diffractograms of lactose and lactose-PEG microparticles.

The ethanol-free formulations demonstrated a decrease in matrix crystallinity with increasing PEG molecular weight (Table 2). The water affinity of PEG decreases with an increase in PEG molecular weight. Using lower molecular weight PEG, the water evaporated at a slower rate and allowed lactose to rearrange into a more crystalline structure in the form of dried particles. The introduction of ethanol in L2 and L3 resulted in an increase in matrix crystallinity, unlike L1 (Table 2). Lactose particles in aqueous solution tend to solidify as amorphous lactose [34]. The addition of ethanol into the feed 
solution might decrease lactose solubility, which in turn reduces the solidified amorphous lactose [35].

\subsection{Physicochemical Characteristics of Chitosan Nanoparticles}

The chitosan nanoparticles had an average particle size of $684.00 \pm 17.61 \mathrm{~nm}$ with a zeta potential of $27.86 \pm 1.27 \mathrm{mV}$. They were spherical with a circularity value of $0.90 \pm 0.23$, a surface roughness $R_{a}$ of $0.38 \pm 0.00 \mathrm{~nm}$ and a crystallinity index of $19.40 \pm 2.23 \%$ (Figure 3).

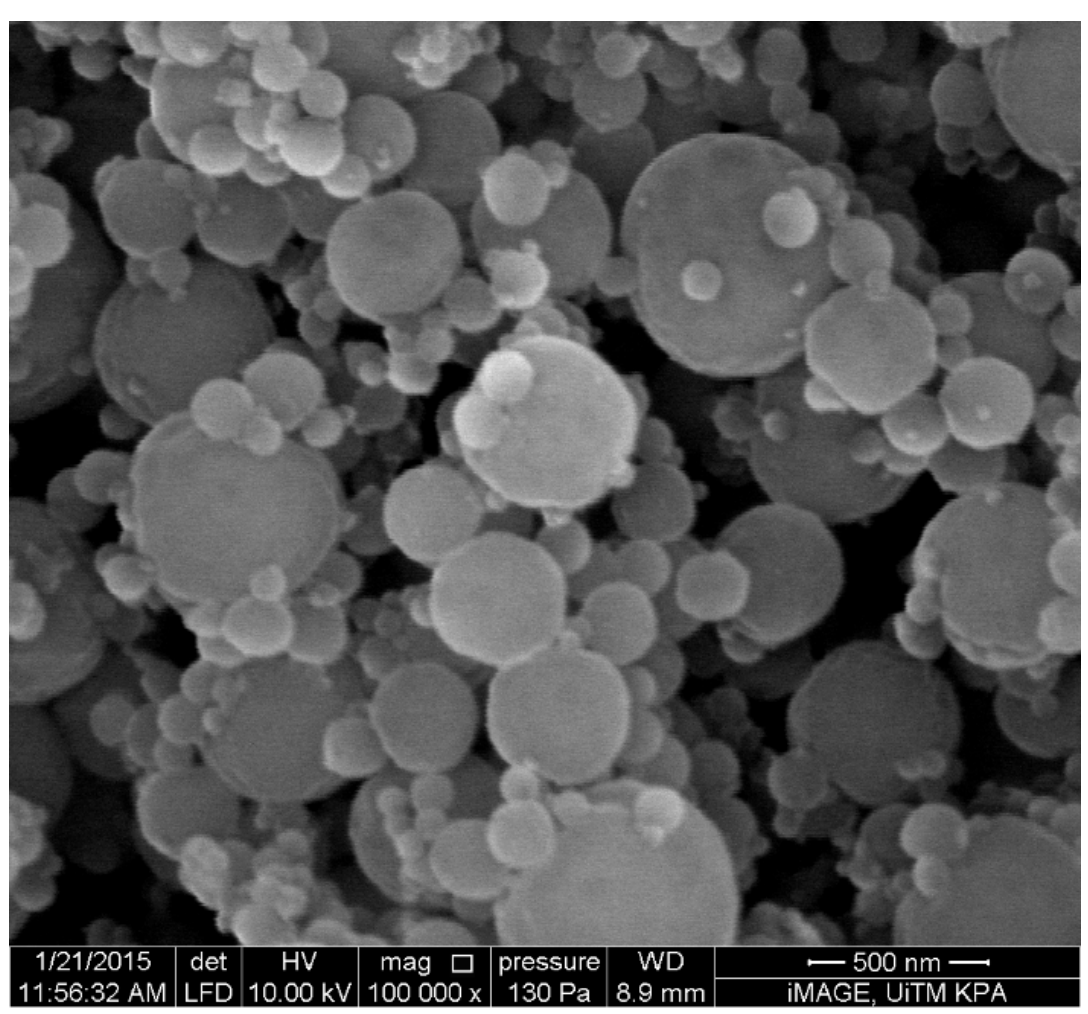

Figure 3. Scanning electron microscopic image of chitosan nanoparticles.

\subsection{Nanoparticle-Microparticle Blend}

L2 and L5 were excluded from the inhalation study due to their high theoretical aerodynamic diameters of $7.37 \pm 0.01$ and $6.69 \pm 0.04 \mu \mathrm{m}$ respectively as inferred by their $d_{50}$ and density values in preliminary trials. Figure 4 showed the distribution profiles of chitosan nanoparticles over lactose-PEG microparticles L1, L3, L4 and L6. Their aerosolization and inhalation profiles are summarized in Table 3.

Chitosan nanoparticles alone without blending with lactose-PEG 3000 microparticles exhibited poor inhalation performances ( $\mathrm{PD}=58.12 \pm 23.30 \%$; $\mathrm{PI}=27.27 \pm 12.62 \%$ ). The inhalation performance is improved when the chitosan nanoparticles were blended with lactose-PEG 3000 microparticles (Table 3). Larger lactose-PEG microparticles $\left(d_{50}\right)$ with smaller specific surface areas brought about a higher respirable fraction of chitosan at the peripheral lung levels (Table 4). A reduction in particle size with an increase in the specific surface area of lactose-PEG microparticles increased its capacity to accommodate more nanoparticles. The mass formed would have a higher chance to deposit on higher stages due to their large mass and thus have reduced amount of nanoparticles reaching the lower stages. The circularity and surface roughness which theoretically had a strong bearing on a specific surface area appeared to play no critical role. 

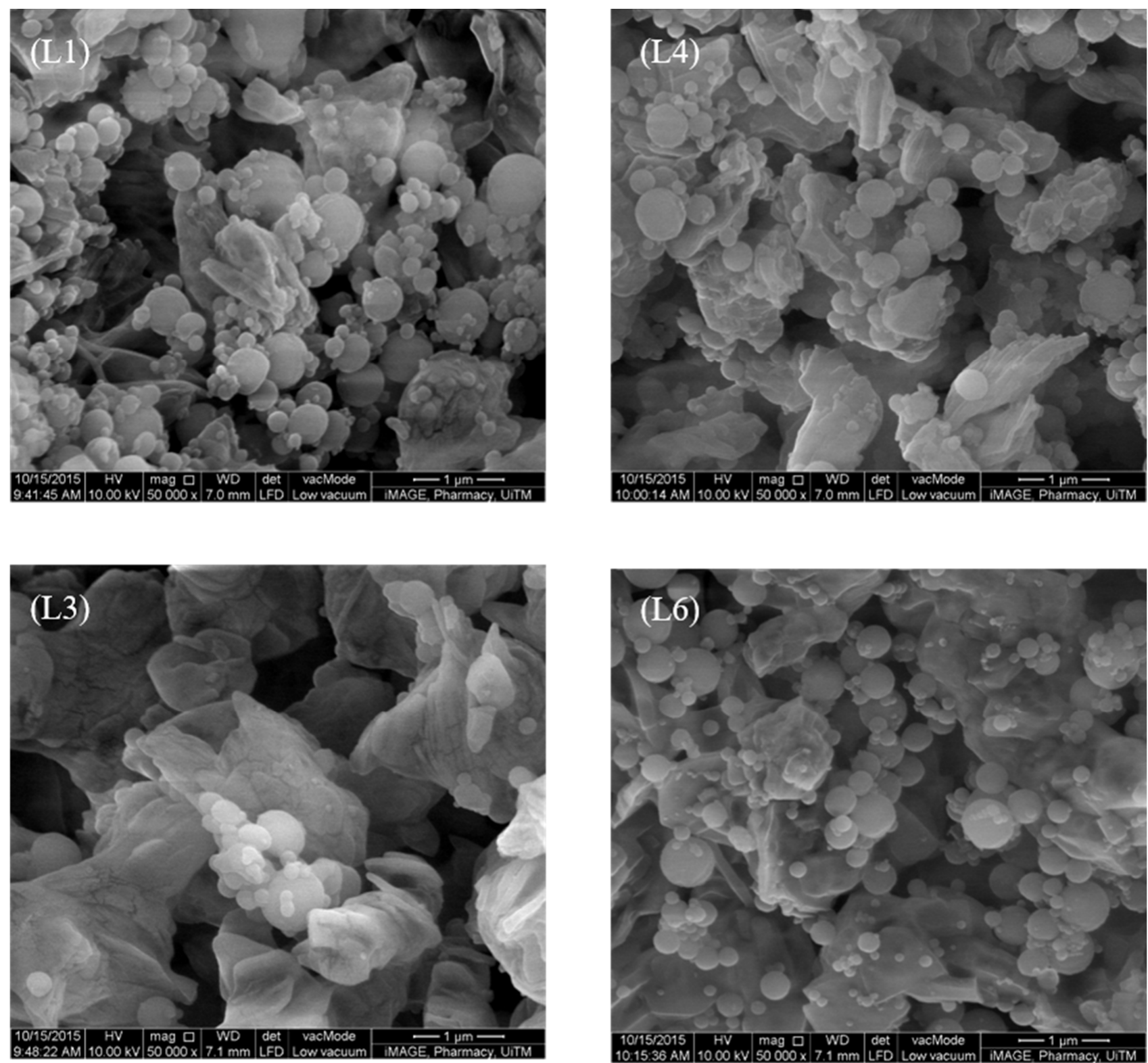

Figure 4. SEM micrographs of chitosan nanoparticle-lactose-PEG microparticle blends.

\subsection{FTIR Study}

The specific surface area and $d_{50}$ of lactose-PEG microparticles exerted the largest effect on deposition manner of the chitosan nanoparticles (Table 4). L3 had the highest specific surface area with the lowest $d_{50}$ values, whereas the opposite was applicable for L6. L3 and L6 were adopted to examine the attachment/detachment behavior of chitosan nanoparticles in an inhaled powder blend. FTIR spectra of the test powder blend collected at each stage were compared against the reference spectra, which constituted of lactose-PEG microparticles, chitosan nanoparticles, and their blend at a weight ratio of 9:1.

The changes in the correlation between the FTIR spectra of the test powder blend and the reference powder reflected the changes in the component ratio in the test powder blend. They did not necessarily reflect the changes in the amount of its components. 
Table 3. Aerosolization and inhalation profiles of chitosan nanoparticles admixed with lactose-PEG microparticles L1, L3, L4 and L6.

\begin{tabular}{|c|c|c|c|c|}
\hline & L1 & L3 & L4 & L6 \\
\hline MMAD $(\mu \mathrm{m})$ & $2.95 \pm 0.17$ & $4.30 \pm 0.85$ & $3.90 \pm 0.92$ & $3.16 \pm 0.30$ \\
\hline GSD & $3.22 \pm 0.60$ & $5.10 \pm 0.35$ & $3.74 \pm 0.19$ & $3.18 \pm 0.40$ \\
\hline TD mg & 15 & 15 & 15 & 15 \\
\hline ED mg & $11.81 \pm 1.39$ & $12.40 \pm 1.80$ & $12.81 \pm 1.65$ & $14.42 \pm 0.49$ \\
\hline DD mg & $4.38 \pm 0.29$ & $6.70 \pm 1.30$ & $6.52 \pm 1.33$ & $7.87 \pm 0.54$ \\
\hline PD (\%) & $78.72 \pm 9.30$ & $82.80 \pm 12.00$ & $85.38 \pm 10.99$ & $96.12 \pm 3.24$ \\
\hline PI (\%) & $29.20 \pm 1.92$ & $44.40 \pm 8.80$ & $43.43 \pm 8.84$ & $52.44 \pm 3.62$ \\
\hline \multicolumn{5}{|l|}{ Particles $<4.5 \mu \mathrm{m}$} \\
\hline FPD (mg) & $3.51 \pm 0.07$ & $4.60 \pm 1.20$ & $4.57 \pm 0.73$ & $6.27 \pm 0.59$ \\
\hline FPF (\%) & $29.95 \pm 2.96$ & $36.96 \pm 4.70$ & $35.58 \pm 1.22$ & $43.47 \pm 3.25$ \\
\hline RF (\%) & $80.40 \pm 6.34$ & $69 \pm 3.90$ & $70.63 \pm 4.20$ & $79.66 \pm 2.86$ \\
\hline \multicolumn{5}{|l|}{ Particles $<3.6 \mu \mathrm{m}$} \\
\hline FPD (mg) & $2.21 \pm 0.27$ & $2.78 \pm 0.85$ & $2.98 \pm 0.24$ & $4.02 \pm 0.52$ \\
\hline FPF (\%) & $18.93 \pm 3.36$ & $22.14 \pm 4.30$ & $23.56 \pm 3.79$ & $27.81 \pm 2.92$ \\
\hline $\mathrm{RF}(\%)$ & $50.43 \pm 3.08$ & $41.23 \pm 5.10$ & $47.12 \pm 10.63$ & $50.94 \pm 3.67$ \\
\hline \multicolumn{5}{|c|}{$0.5 \mu \mathrm{m}<$ Particles $<3.6 \mu \mathrm{m}$} \\
\hline FPD (mg) & $1.79 \pm 0.128$ & $1.98 \pm 0.61$ & $2.58 \pm 0.22$ & $3.58 \pm 0.55$ \\
\hline FPF $(\%)$ & $15.39 \pm 2.74$ & $15.75 \pm 3.08$ & $20.44 \pm 3.72$ & $24.77 \pm 3.32$ \\
\hline $\mathrm{RF}(\%)$ & $40.97 \pm 1.97$ & $29.31 \pm 3.70$ & $40.94 \pm 10.27$ & $45.32 \pm 4.09$ \\
\hline
\end{tabular}

MMAD: mass median aerodynamic diameter; GSD: geometric standard deviation; TD: total dose; ED: emitted dose; DD: deposited dose; PD: percent dispersed; PI: percent inhaled; FPD: fine particle dose; FPF: fine particle fraction; RF: respirable fraction.

Table 4. Pearson correlation of fine particle and respirable fractions of chitosan nanoparticles with physicochemical characteristics of lactose-PEG microparticles L1, L3, L4 and L6.

\begin{tabular}{|c|c|c|c|c|c|c|c|}
\hline & $\mathbf{r}$ & $p$ & & $\mathbf{r}$ & $p$ & $\mathbf{r}$ & $p$ \\
\hline \multicolumn{3}{|c|}{$\mathrm{FPF}_{<4.5}$} & $\mathrm{FPF}_{<3.6}$ & \multicolumn{4}{|c|}{$0.5<\mathrm{FPF}_{<3.6}$} \\
\hline $\begin{array}{l}\text { Crystallinity (Peak } \\
\text { area }_{\left.2 \theta=19.98^{\circ}\right)}\end{array}$ & -0.670 & 0.330 & & -0.571 & 0.429 & -0.296 & 0.704 \\
\hline$p b\left(\mathrm{~g} / \mathrm{cm}^{3}\right)$ & -0.701 & 0.299 & & -0.620 & 0.380 & -0.362 & 0.638 \\
\hline$p t\left(\mathrm{~g} / \mathrm{cm}^{3}\right)$ & -0.205 & 0.795 & & 0.055 & 0.945 & 0.372 & 0.628 \\
\hline Carr's Index (\%) & 0.532 & 0.468 & & 0.684 & 0.316 & 0.720 & 0.280 \\
\hline Hausner Ratio & 0.436 & 0.564 & & 0.606 & 0.394 & 0.669 & 0.331 \\
\hline Circ & 0.301 & 0.699 & & 0.426 & 0.574 & 0.418 & 0.582 \\
\hline $\mathrm{Ra}(\mathrm{nm})$ & -0.324 & 0.676 & & -0.504 & 0.496 & -0.583 & 0.417 \\
\hline Specific surface area $\left(\mathrm{m}^{2} / \mathrm{g}\right)$ & -0.272 & 0.728 & & -0.446 & 0.554 & -0.703 & 0.297 \\
\hline $\mathrm{D}_{[4,3]}(\mu \mathrm{m})$ & -0.202 & 0.798 & & -0.342 & 0.658 & -0.361 & 0.639 \\
\hline $\mathrm{D}_{[3,2]}(\mu \mathrm{m})$ & 0.380 & 0.620 & & 0.530 & 0.470 & 0.753 & 0.247 \\
\hline Span & -0.288 & 0.712 & & -0.522 & 0.478 & -0.776 & 0.224 \\
\hline $\mathrm{d}_{10}(\mu \mathrm{m})$ & 0.568 & 0.432 & & 0.693 & 0.307 & 0.860 & 0.140 \\
\hline $\mathrm{d}_{50}(\mu \mathrm{m})$ & 0.192 & 0.808 & & 0.361 & 0.639 & 0.629 & 0.371 \\
\hline \multirow[t]{2}{*}{$\mathrm{d}_{90}(\mu \mathrm{m})$} & -0.503 & 0.497 & & -0.652 & 0.348 & -0.680 & 0.320 \\
\hline & & & $\mathrm{RF}_{<3.6}$ & \multicolumn{4}{|c|}{$0.5<\mathrm{RF}_{<3.6}$} \\
\hline $\begin{array}{l}\text { Crystallinity (Peak } \\
\text { area }_{2 \theta=19.98^{\circ}} \text { ) }\end{array}$ & 0.744 & 0.256 & & 0.686 & 0.314 & 0.468 & 0.532 \\
\hline$p b\left(\mathrm{~g} / \mathrm{cm}^{3}\right)$ & 0.724 & 0.276 & & 0.635 & 0.365 & 0.401 & 0.599 \\
\hline$p t\left(\mathrm{~g} / \mathrm{cm}^{3}\right)$ & 0.311 & 0.689 & & 0.685 & 0.315 & 0.777 & 0.223 \\
\hline Carr's Index (\%) & -0.363 & 0.637 & & 0.044 & 0.956 & 0.346 & 0.654 \\
\hline Hausner Ratio & -0.362 & 0.638 & & 0.067 & 0.933 & 0.363 & 0.637 \\
\hline Circ & -0.648 & 0.352 & & -0.251 & 0.749 & 0.041 & 0.959 \\
\hline $\mathrm{R}_{\mathrm{a}}(\mathrm{nm})$ & 0.398 & 0.602 & & -0.044 & 0.956 & -0.331 & 0.669 \\
\hline
\end{tabular}


Table 4. Cont

\begin{tabular}{|c|c|c|c|c|c|c|}
\hline & $\mathbf{r}$ & $p$ & $\mathbf{r}$ & $p$ & $\mathbf{r}$ & $p$ \\
\hline Specific surface area $\left(\mathrm{m}^{2} / \mathrm{g}\right)$ & -0.803 & 0.197 & $-0.964 *$ & 0.036 & $-0.989 *$ & 0.011 \\
\hline $\mathrm{D}_{[4,3]}(\mu \mathrm{m})$ & 0.634 & 0.366 & 0.222 & 0.778 & -0.058 & 0.942 \\
\hline $\mathrm{D}_{[3,2]}(\mu \mathrm{m})$ & 0.808 & 0.192 & 0.936 & 0.064 & $0.963 *$ & 0.037 \\
\hline Span & -0.408 & 0.592 & -0.765 & 0.235 & -0.920 & 0.080 \\
\hline $\mathrm{d}_{10}(\mu \mathrm{m})$ & 0.715 & 0.285 & 0.840 & 0.160 & 0.908 & 0.092 \\
\hline $\mathrm{d}_{50}(\mu \mathrm{m})$ & 0.855 & 0.145 & 0.986 * & 0.014 & 0.979 * & 0.021 \\
\hline $\mathrm{d}_{90}(\mu \mathrm{m})$ & 0.412 & 0.588 & 0.004 & 0.996 & -0.300 & 0.700 \\
\hline
\end{tabular}

* Correlation is significant at the 0.05 level (2-tailed). pb: bulk density; pt: tapped density; Ra: surface roughness; $\mathrm{D}_{[4,3]}$ : volume weighted mean diameter; $D_{[3,2]}$ : surface area weighted mean diameter; $d_{10}$ : particle diameter corresponding to $10 \%$ undersized fraction; $d_{50}$ : particle diameter corresponding to $50 \%$ undersized fraction; $\mathrm{d}_{90}$ : particle diameter corresponding to $90 \%$ undersized fraction; FPF: fine particle fraction; RF: respirable fraction.

With reference to L3 and L6, marked correlation changes between spectra took place after stage 2 to 3 (Table 5). The spectra of the test powder blend collected between stage 0 and 3 were highly correlated to those of reference powder blend and lactose-PEG $3000 \mathrm{mi}-$ croparticles, the main component in a powder blend. At stages 0 to 3 generally, the chitosan nanoparticles were admixed with the lactose particles. At stages 4, 5 and 6, the weight ratio of chitosan nanoparticles to lactose-PEG 3000 microparticles appeared to be higher. At stage 7, the primary component in the test powder blend was chitosan nanoparticles. The test powder blend at stage 7 exhibited a sharp reduction in lactose-PEG 3000 microparticle fraction.

Table 5. FTIR spectra correlations of L3 and L6 admixed chitosan nanoparticles against chitosan nanoparticles, lactose-PEG 3000 microparticles and their blend.

\begin{tabular}{ccccccc}
\hline \multicolumn{3}{c}{ L3 } & & & L6 \\
\hline Stage & $\begin{array}{c}\text { Chitosan } \\
\text { Nanoparticles }\end{array}$ & $\begin{array}{c}\text { Lactose-PEG 3000 } \\
\text { Microparticles }\end{array}$ & Blend & $\begin{array}{c}\text { Chitosan } \\
\text { Nanoparticles }\end{array}$ & $\begin{array}{c}\text { Lactose-PEG 3000 } \\
\text { Microparticles }\end{array}$ & Blend \\
\hline 0 & $0.5316 \pm 0.013$ & $0.9815 \pm 0.007$ & $0.9888 \pm 0.005$ & $0.5280 \pm 0.009$ & $0.9809 \pm 0.005$ & $0.9868 \pm 0.003$ \\
1 & $0.5338 \pm 0.009$ & $0.9578 \pm 0.006$ & $0.9838 \pm 0.007$ & $0.5530 \pm 0.007$ & $0.9228 \pm 0.006$ & $0.9365 \pm 0.006$ \\
2 & $0.5279 \pm 0.008$ & $0.9482 \pm 0.008$ & $0.9882 \pm 0.004$ & $0.6029 \pm 0.013$ & $0.8754 \pm 0.022$ & $0.8963 \pm 0.020$ \\
3 & $0.5755 \pm 0.010$ & $0.9545 \pm 0.003$ & $0.9832 \pm 0.001$ & $0.6064 \pm 0.006$ & $0.7437 \pm 0.014$ & $0.7743 \pm 0.016$ \\
4 & $0.7013 \pm 0.046$ & $0.8406 \pm 0.031$ & $0.8228 \pm 0.030$ & $0.6960 \pm 0.001$ & $0.7638 \pm 0.019$ & $0.7936 \pm 0.019$ \\
5 & $0.7093 \pm 0.012$ & $0.9120 \pm 0.001$ & $0.8861 \pm 0.004$ & $0.6879 \pm 0.010$ & $0.8523 \pm 0.016$ & $0.8727 \pm 0.011$ \\
6 & $0.6527 \pm 0.007$ & $0.9186 \pm 0.004$ & $0.8931 \pm 0.005$ & $0.6783 \pm 0.059$ & $0.7688 \pm 0.054$ & $0.7668 \pm 0.060$ \\
7 & $0.9281 \pm 0.005$ & $0.4965 \pm 0.010$ & $0.5546 \pm 0.011$ & $0.9203 \pm 0.008$ & $0.3968 \pm 0.007$ & $0.4392 \pm 0.002$ \\
\hline
\end{tabular}

\section{Conclusions}

An inhalable microparticulate carrier can be used successfully to deliver nanoparticles in a form of coarse carrier-free dry powder inhaler. The specific surface area of the small microparticle carriers significantly affects the nanoparticle deposition on the airway. Larger microparticle carriers enhance the peripheral lung deposition of nanoparticles. They are characterized by a reduced specific surface area, which in turn facilitates the detachment of nanoparticles from the microparticle carrier and into the lower lung regions during inhalation. Unlike the blend of large carriers and nanoparticles [36], the inhalation efficiency of nanoparticles does not depend on shape and crystallinity of the microparticle carrier. Future studies shall focus on therapeutic loaded nanocarriers and their inhalational profiling through the aid of microparticle carriers in accordance with the compendial guidelines, and will examine the industry-relevance of microparticle carriers and its blend with nanocarriers. The therapeutic loading into nanoparticles is expected to be accompanied by a variation in their size, zeta potential and morphological characteristics. The critical inhalational quality attributes of microparticle carriers of a physical blend with the nanoparticles theoretically would remain unchanged. The required scale of these quality attributes, such 
as the magnitude of size and specific surface area, may however differ as a function of the physical characteristics of the therapeutic loaded nanoparticles. Further optimization of the particulate quality attributes is deemed necessary with reference to an in vivo application where the biological lung is characterized by a more complex anatomical structure and an electrostatic nature that has a strong bearing on particle flow and mucosal adhesion [37].

Author Contributions: Data curation, N.A. and T.W.W.; Formal analysis, N.A., P.C., E.Q. and T.W.W.; Funding acquisition, T.W.W.; Investigation, N.A. and I.N.; Methodology, N.A. and T.W.W.; Resources, T.W.W.; Supervision, T.W.W.; Validation, N.A., I.N., P.C. and T.W.W.; Writing-original draft, N.A.; Writing-review \& editing, P.C. and T.W.W. All authors have read and agreed to the published version of the manuscript.

Funding: This research was funded by Ministry of Science, Technology and Innovation, grant number IF0402Q1226, and Ministry of Higher Education Malaysia, grant number LRGS-NanoMITe RU029-2014.

Institutional Review Board Statement: Not applicable.

Informed Consent Statement: Not applicable.

Data Availability Statement: The data presented in this study are available on request from the corresponding author.

Conflicts of Interest: The authors declare no conflict of interest. The funders had no role in the design of the study; in the collection, analyses, or interpretation of data; in the writing of the manuscript, and in the decision to publish the results.

\section{Abbreviations}

FTIR: Fourier transform infrared spectroscopy; PEG: polyethylene glycol; SEM: scanning electron microscope; XRPD: X-ray powder diffractometer.

\section{References}

1. Zhou, Q.T.; Morton, D.A.V. Drug-lactose binding aspects in adhesive mixtures: Controlling performance in dry powder inhaler formulations by altering lactose carrier surfaces. Adv. Drug Deliv. Rev. 2012, 64, 275-284. [CrossRef]

2. Pinto, J.T.; Zellnitz, S.; Guidi, T.; Roblegg, E.; Paudel, A. Assessment of dry powder inhaler carrier targeted design: A comparative case study of diverse anomeric compositions and physical properties of lactose. Mol. Pharm. 2018, 15, 2827-2839. [CrossRef] [PubMed]

3. Lee, H.J.; Lee, H.G.; Kwon, Y.B.; Kim, J.Y.; Rhee, Y.S.; Chon, J.; Park, E.S.; Kim, D.W.; Park, C.W. The role of lactose carrier on the powder behavior and aerodynamic performance of bosentan microparticles for dry powder inhalation. Eur. J. Pharm. Sci. 2018, 117, 279-289. [CrossRef] [PubMed]

4. Molina, C.; Kaialy, W.; Chen, Q.; Commandeur, D.; Nokhodchi, A. Agglomerated novel spray-dried lactose-leucine tailored as a carrier to enhance the aerosolization performance of salbutamol sulfate from DPI formulations, Drug Deliv. Transl. Res. 2018, 8, 1769-1780. [CrossRef]

5. Smyth, H.D.C.; Hickey, A.J. Carriers in Drug Powder Delivery, Am. J. Drug Deliv. 2005, 3, 117-132. [CrossRef]

6. Odziomek, M.; Sosnowski, T.R.; Gradon, L. Conception, preparation and properties of functional carrier particles for pulmonary drug delivery. Int. J. Pharm. 2012, 433, 51-59. [CrossRef] [PubMed]

7. Sheshala, R.; Anuar, N.K.; Samah, N.H.A.; Wong, T.W. In vitro drug dissolution/permeation testing of nanocarriers for skin application: A comprehensive review. AAPS PharmSciTech. 2019, 20, 164. [CrossRef] [PubMed]

8. Smola, M.; Vandamme, T.; Sokolowski, A. Nanocarriers as pulmonary drug delivery systems to treat and to diagnose respiratory and non respiratory diseases. Int. J. Nanomed. 2008, 3, 1-19.

9. Patil, T.S.; Deshpande, A.S. Mannosylated nanocarriers mediated site-specific drug delivery for the treatment of cancer and other infectious diseases: A state of the art review. J. Control. Release 2020, 320, 239-252. [CrossRef] [PubMed]

10. Bharathi, D.; Ranjithkumar, R.; Chandarshekar, B.; Bhuvaneshwari, V. Bio-inspired synthesis of chitosan/copper oxide nanocomposite using rutin and their anti-proliferative activity in human lung cancer cells. Int. J. Biol. Macromol. 2019, 141, 476-483. [CrossRef]

11. Chi, J.; Jiang, Z.; Qiao, J.; Peng, Y.; Liu, W.; Han, B. Synthesis and anti-metastasis activities of norcantharidin-conjugated carboxymethyl chitosan as a novel drug delivery system. Carbohydr. Polym. 2019, 214, 80-89. [CrossRef]

12. Cirillo, G.; Vittorio, O.; Kunhardt, D.; Valli, E.; Voli, F.; Farfalla, A.; Curcio, M.; Spizzirri, U.G.; Hampel, S. Combining carbon nanotubes and chitosan for the vectorization of methotrexate to lung cancer cells. Materials 2019, 12, 2889. [CrossRef] 
13. Li, W.; Hu, X.; Wang, S.; Xing, Y.; Wang, H.; Nie, Y.; Liu, T.; Song, K. Multiple comparisons of three different sources of biomaterials in the application of tumor tissue engineering in vitro and in vivo. Int. J. Biol. Macromol. 2019, 130, 166-176. [CrossRef]

14. Pandey, P.; Dua, K.; Dureja, H. Erlotinib loaded chitosan nanoparticles: Formulation, physicochemical characterization and cytotoxic potential. Int. J. Biol. Macromol. 2019, 139, 1304-1316. [CrossRef] [PubMed]

15. Tao, L.; Jiang, J.; Gao, Y.; Wu, C.; Liu, Y. Biodegradable alginate-chitosan hollow nanospheres for codelivery of doxorubicin and paclitaxel for the effect of human lung cancer A549 cells. Biomed Res. Int. 2018, 2018, 4607945. [CrossRef] [PubMed]

16. Wang, F.; Wang, Y.; Ma, Q.; Cao, Y.; Yu, B. Development and characterization of folic acid-conjugated chitosan nanoparticles for targeted and controlled delivery of gemcitabinein lung cancer therapeutics. Artif. Cells Nanomed. Biotechnol. 2017, 45, 1530-1538. [CrossRef] [PubMed]

17. Shah, K.; Chan, L.W.; Wong, T.W. Critical physicochemical and biological attributes of nanoemulsions for pulmonary delivery of rifampicin by nebulization technique in tuberculosis treatment. Drug Deliv. 2017, 24, 1631-1647. [CrossRef]

18. Rosière, R.; van Woensel, M.; Gelbcke, M.; Mathieu, V.; Hecq, J.; Mathivet, T.; Vermeersch, M.; van Antwerpen, P.; Amighi, K.; Wauthoz, N. New folate-grafted chitosan derivative to improve delivery of paclitaxel-loaded solid lipid nanoparticles for lung tumor therapy by inhalation. Mol. Pharm. 2018, 15, 899-910. [CrossRef]

19. Yang, W.; Peters, J.I.; Williams, R.O. Inhaled nanoparticles-A current review. Int. J. Pharm. 2008, 356, 239-247. [CrossRef]

20. Alhajj, N.; Zakaria, Z.; Naharudin, I.; Ahsan, F.; Li, W.; Wong, T.W. Critical physicochemical attributes of chitosan nanoparticles admixed lactose-PEG 3000 microparticles in pulmonary inhalation. Asian J. Pharm. Sci. 2020, 12, 374-384. [CrossRef]

21. Agnihotri, S.A.; Mallikarjuna, N.N.; Aminabhavi, T.M. Recent advances on chitosan-based micro- and nanoparticles in drug delivery. J. Control. Release 2004, 100, 5-28. [CrossRef]

22. Pilcer, G.; Amighi, K. Formulation strategy and use of excipients in pulmonary drug delivery. Int. J. Pharm. 2010, 392, 1-19. [CrossRef]

23. Luo, Y.; Zhang, Z.; Huang, G.; Yu, H.; Ma, Y.; Zheng, Q.; Yue, P. Roles of maltodextrin and inulin as matrix formers on particle performance of inhalable drug nanocrystal-embedded microparticles. Carbohydr. Polym. 2020, 235, 115937. [CrossRef] [PubMed]

24. Zeng, X.M.; Martin, G.P.; Marriott, C.; Pritchard, J. The influence of carrier morphology on drug delivery by dry powder inhalers. Int. J. Pharm. 2000, 200, 93-106. [CrossRef]

25. Zeng, X.M.; Martin, G.P.; Marriott, C.; Pritchard, J. Lactose as a carrier in dry powder formulations: The influence of surface characteristics on drug delivery. J. Pharm. Sci. 2001, 90, 1424-1434. [CrossRef] [PubMed]

26. Rasul, S.M.; Muniandy, M.T.A.; Zakaria, Z.; Shah, K.; Chee, C.F.; Dabbagh, A.; Rahman, N.A.; Wong, T.W. A review on chitosan and its development as pulmonary particulate anti-infective and anti-cancer drug carriers. Carbohydr. Polym. 2020, 250, 116800. [CrossRef] [PubMed]

27. Garbuzenko, O.B.; Mainelis, G.; Taratula, O.; Minko, T. Inhalation treatment of lung cancer: The influence of composition, size and shape of nanocarriers on their lung accumulation and retention. Cancer Biol. Med. 2014, 11, 44-55. [PubMed]

28. Mehta, P. Dry powder inhalers: A focus on advancements in novel drug delivery systems. J. Drug Deliv. 2016, $2016,8290963$. [CrossRef]

29. Segal, L.; Creely, J.J.; Martin, A.E.; Conrad, C.M. An empirical method for estimating the degree of crystallinity of native cellulose using the X-ray diffractometer. Text. Res. J. 1959, 29, 786-794. [CrossRef]

30. Kumar, A.B.V.; Varadaraj, M.C.; Lalitha, R.G.; Tharanathan, R.N. Low molecular weight chitosans: Preparation with the aid of papain and characterization. Biochim. Biophys. Acta-Gen. Subj. 2004, 1670, 137-146. [CrossRef]

31. Haglund, B.O. Solubility studies of polyethylene glycols in ethanol and water. Thermochim. Acta 1987, 114, 97-102. [CrossRef]

32. Chidavaenzi, O.C.; Buckton, G.; Koosha, F. The effect of co-spray drying with polyethylene glycol 4000 on the crystallinity and physical form of lactose. Int. J. Pharm. 2001, 216, 43-49. [CrossRef]

33. Corrigan, D.O.; Healy, A.M.; Corrigan, O.I. The effect of spray drying solutions of polyethylene glycol (PEG) and lactose/PEG on their physicochemical properties. Int. J. Pharm. 2002, 235, 193-205. [CrossRef]

34. Hellrup, J.; Mahlin, D. Confinement of amorphous lactose in pores formed upon co-spray drying with nanoparticles. J. Pharm. Sci. 2017, 106, 322-330. [CrossRef]

35. Harjunen, P.; Lehto, V.P.; Valisaari, J.; Lankinen, T. Effecst of ethanol to water ratio in feed solution on the crystallinity of spray-dried lactose. Drug Dev. Ind. Pharm. 2002, 28, 949-955. [CrossRef] [PubMed]

36. Noraizaan, A.N.; Wong, T.W. Physicochemical effects of lactose microcarrier on inhalation performance of rifampicin in polymeric nanoparticles. Powder Technol. 2017, 310, 272-281. [CrossRef]

37. Hogg, J.C. Response of the lung to inhaled particles. Med. J. Aust. 1985, 142, 675. [CrossRef] [PubMed] 